\title{
ETIOLOGICAL AND PATHOMORPHOLOGICAL INVESTIGATIONS OF CORONAVIRUS AND ROTAVIRUS GASTROENTERITIS IN GOAT KIDS AND LAMBS
}

\author{
Ismet Kalkanov', Ivan Dinev ${ }^{1}$, Ivan Zarkov² \\ ${ }^{1}$ Department of General and Clinical Pathology, Faculty of Veterinary Medicine, \\ Trakia University, Student Campus, 6000 Stara Zagora, Bulgaria \\ ${ }^{2}$ Department of Veterinary Microbiology, Infectious and Parasitic Diseases, \\ Faculty of Veterinary Medicine, Trakia University, Student Campus, \\ 6000 Stara Zagora, Bulgaria
}

Received 5 October 2020; Received in revised form 18 January 2021; Accepted 23 February 2021

\begin{abstract}
The aim of the performed field and laboratory investigations was to determine the commonest enteropathogens in neonatal and juvenile lambs and goat kids, as well as induced macro- and microscopic alterations in the different digestive system compartments. The study comprised a total of 850 newborn and juvenile lambs (600) and goat kids (250) from 9 private dairy farms (3 goat farms, 6 sheep farms). The age of animals was from 24 hours to 20 days. The following rapid antigen detection tests were used: (Rainbow calf scour 5 BIO K 306, Monoclonal Antibody anti-Coronavirus and Rotavirus FITC conjugated, BIOX Diagnostics, Belgium). Gross anatomy and histopathological examination of tissue samples was performed on 21 carcasses (9 goat kids and 12 lambs) from animals that died with signs of gastroenteritis. The main detected agents of intestinal infections were Cryptosporidium parvum, rotaviruses, coronaviruses and Escherichia coli.
\end{abstract}

Key words: pathology, goat kids, lambs, gastroenteritis, coronavirus, rotavirus

\section{INTRODUCTION}

Gastrointestinal diseases in lambs and goat kids are a complex multifactorial syndrome (1). Their occurrence is directly related to the susceptibility of animals to diseases, the nutritional and immune status of the flock, environmental factors, farm management, and the synergic action of diverse infectious agents. All of these factors are prerequisites for the occurrence of intestinal illnesses $(2,3)$. Neonatal diarrhea observed in goat kids and lambs up to 21 days of age is one of the most common diseases

Corresponding author: Assist. Prof. Ismet Kalkanov, $\mathrm{PhD}$

E-mail address: ismet_88@abv.bg

Present address: Department of General and Clinical Pathology, Faculty of Veterinary Medicine, Trakia University, Student Campus, 6000 Stara

Zagora, Bulgaria

Phone: +359888452098

Copyright: (C) 2021 Kalkanov I. This is an open-access article published under the terms of the Creative Commons Attribution License which

permits unrestricted use, distribution, and reproduction in any medium, provided the original author and source are credited.

Competing Interests: The authors have declared that no competing interests exist.

Available Online First: 6 April 2021

Published on: 15 October 2021

https://doi.org/10.2478/macvetrev-2021-0015 associated with high morbidity and mortality rates in this category of livestock (4), which vary from $25 \%$ to $50 \%$ depending on housing conditions and farm management (2). Retarded growth and development of newborn goat kids and lambs suffering from gastroenterites increase treatment costs, whereas high morbidity and mortality rates incur substantial economic losses to farmers $(5,6)$.

The most common etiological agents of diarrhea in lambs and goat kids during the first month of life are Escherichia coli, Cryptosporidium spp., Giardia spp., Salmonella spp. and Clostridium spp. Among viral agents, rotaviruses, adenoviruses, herpesviruses and coronaviruses have been detected (7). Adenoviruses were reported in intestinal diseases in humans, pigs, horses, sheep, goats and dogs (8). Affected animals die within 1 to 4 days after clinical manifestations, with macroscopic changes in the gastrointestinal tract (9).

Observed clinical signs of enteritis in goat kids and lambs include depression, inability to move, and in some animals - prolonged recumbency. The 
feces can be soft, watery, yellowish, sometimes mixed with mucus and blood, and foul-smelling. Dehydration, loss of skin elasticity, perianal area stained with diarrhoeic feces, ruffled hair, dry nostrils, fever, accelerated heart and respiratory rates are frequently observed (10).

Described gross pathology changes in intestines consisted of hyperemia of mesenteric blood vessels, mesenteric lymphadenopathy, ballooned small and large intestines. The intestinal mucosa was oedematous and spattered with hemorrhages (11).

Histopathological changes in intestines were vascular hyperemia, submucosal edema, desquamation of the epithelium (without intranuclear inclusion bodies), erosions and ulceration of the epithelial lining with infiltration of inflammatory cells in the submucosa. In some cases, total necrosis of intestinal villi along with infiltration of propria mucosae with neutrophils was reported (4).

Based on literature data analysis and the importance of the problem, our investigations aimed to identify etiological agents of gastrointestinal disorders in neonates and juvenile small ruminants and to perform detailed pathomorphological examinations.

\section{MATERIAL AND METHODS}

The study was carried out on 850 neonate and juvenile lambs (600), and goat kids (250) from 9 private dairy farms (3 goat farms, 6 sheep farms).
The age of animals was from 24 hours to 20 days. Clinical and epidemiological examinations were performed onsite at the farms.

Rapid tests were used for the detection of five agents, Rainbow calf scour 5 BIO K 306 was used for detection of Rota, Corona, E. coli F5, Crypto, and Clostridium perf. in the bovine stool (BIOX Diagnostics, Belgium). Twenty-one carcasses (9 goat kids and 12 lambs) which prior dead manifested enteric disorders were submitted to gross anatomy studies. Tissue samples $(1 \mathrm{x} 1 \mathrm{~cm})$ were collected from affected compartments of the proximal and distal gastrointestinal tract: abomasum, duodenum, jejunum with mesenteric lymph nodes, ileum, caecum, colon and rectum - with $2.5 \mathrm{~cm}$ length. Specimens were fixed in 10\% neutral buffered formalin for $48-72 \mathrm{~h}$ and embedded in paraffin. From paraffin blocks, $4 \mu \mathrm{m}$ sections were cut on a Leica RM 2235 microtome and stained routinely with hematoxylin-eosin (H/E). Tissue samples were obtained from lungs and intestinal segments (abomasum, duodenum, jejunum with mesenteric lymph nodes, ileum, caecum, colon and rectum) for immunofluorescence assays. A monoclonal conjugated antibody - Monoclonal Antibody anti Coronavirus and Rotavirus FITC conjugated $0.5 \mathrm{ml}$ (20X), BIO 023, (BIOX Diagnostics, Belgium) was used. Tissue samples were also submitted to immunohistochemical tests using Coronavirus pan Monoclonal Antibody (FIPV3-70): sc65653, $1 \mathrm{mg} / \mathrm{ml}$, (Santa Cruz Biotechnology, Germany).

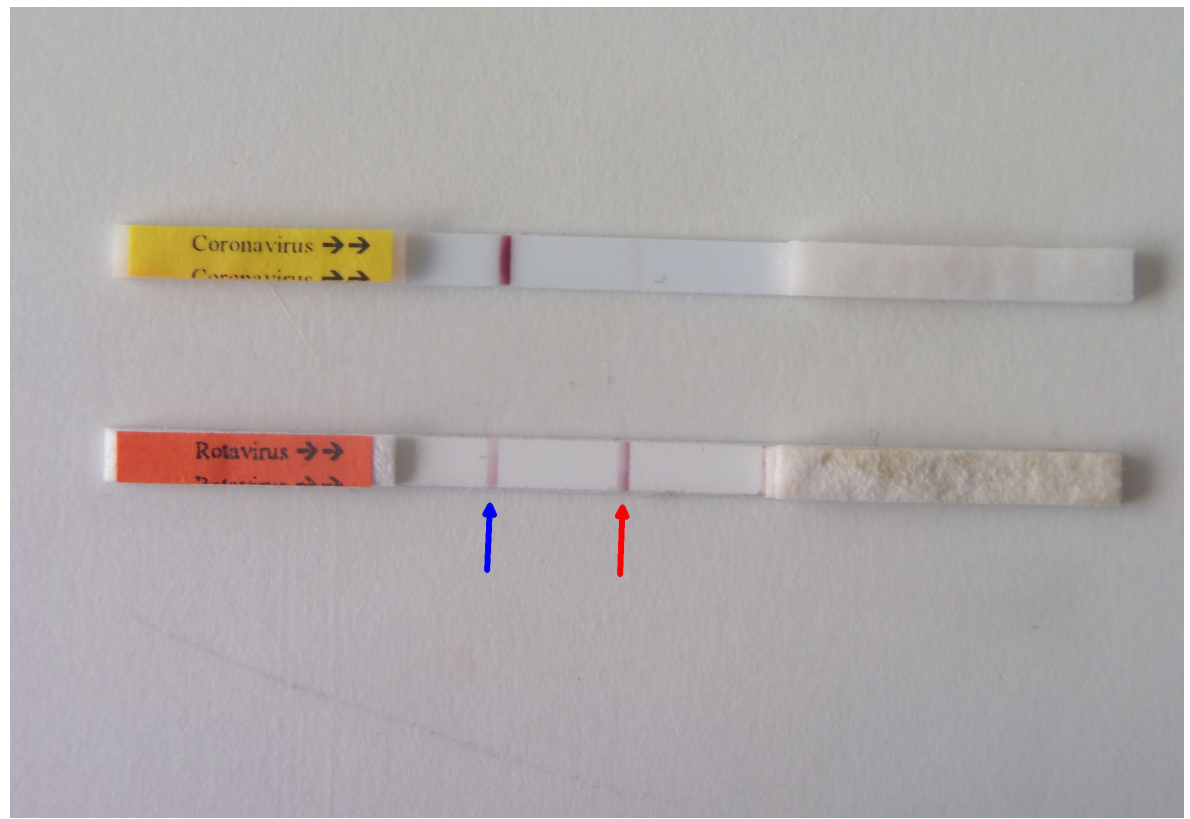

Figure 1. Positive results for presence of rotavirus and coronavirus antigens in faecal samples from 223 diarrhoeic goat kids and lambs (blue arrow: control line; red arrow: positive result) 


\section{RESULTS}

The epidemiological studies performed on 9 farms ( 3 goat farms and 6 sheep farms) proved the presence of gastroenterites in newborn, growing lambs and goat kids. The clinical findings included dehydration, weight loss, prolonged recumbency and stained perineal areas with diarrhoeic feces.

\section{Antigenic tests}

The performed antigenic tests proved that $50 \%$ of the detected cases with gastroenteritis were associated with complex infections including virus, protozoan and bacterial agents (Cryptosporidium parvum, rotaviruses, coronaviruses and Escherichia coli) (Fig. 1).

In $35 \%$ of the cases, only Cryptosporidium parvum was detected, whereas in $15 \%$ - coronaand rotaviruses were detected (Table 1).

Table 1. Results of the screening for the enteropathogens

\begin{tabular}{lc}
\hline Pathogen & Positive samples \\
\hline $\begin{array}{l}\text { Cryptosporidium parvum, rotaviruses, } \\
\text { coronaviruses and Escherichia coli }\end{array}$ & $50 \%$ \\
Cryptosporidium parvum & $35 \%$ \\
Rotavirus and coronavirus & $15 \%$ \\
\hline
\end{tabular}

\section{Pathoanatomical examinations}

Twenty-one carcasses (9 goat kids and 12 lambs) with clinical manifestations of gastrointestinal diseases were necropsied. The external appearance of bodies revealed dehydration and emaciation. The perianal region and tail-base were stained with yellow-green and bloody diarrheic feces. The investigation of abdominal organs demonstrated macroscopic changes in the digestive organs. Small and large intestines showed changes specific for catarrhal to catarrhal-hemorrhagic enterocolitis, and in cases of cryptosporidiosis-hemorrhagic colitis. Intestinal wall serosa was hyperemic, extremely thinned with intestinal content that filled the intestinal lumen along its entire length (Fig. 2).

Mesenteric lymph nodes were edematous and affected, while vessels were filled with blood. Incision of the intestinal mucosa showed that it was very thinned and lined with mucinous yellowish content, and the abomasum was dilated and overfilled with milk coagulum in cases of rotavirus enteritis (Fig. 3).

In coronavirus enteritis, intestinal content had a greenish color, with gas bubbles and feed particles. Incision of the thoracic cavity along the periphery of lungs revealed pale areas crepitating upon palpationemphysema. The trachea and main bronchi were filled with white fluid mixed with air bubbles-edema. No changes were found on the pericardial sac, except in

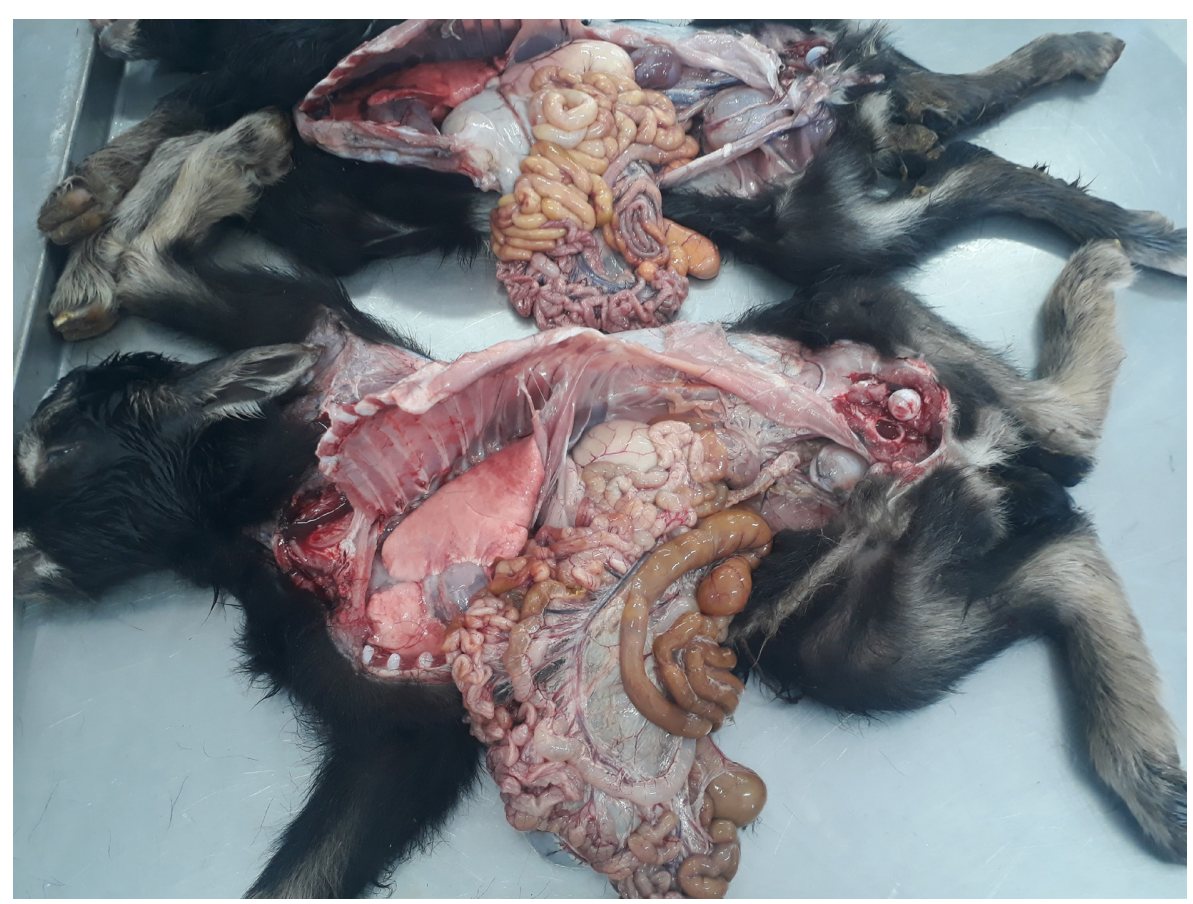

Figure 2. Gas-filled small and large intestines - meteorism. Hyperaemic and strongly thinned intestinal wall with prominating whitish-yellow intestinal content in goat kids with coronavirus enteritis 


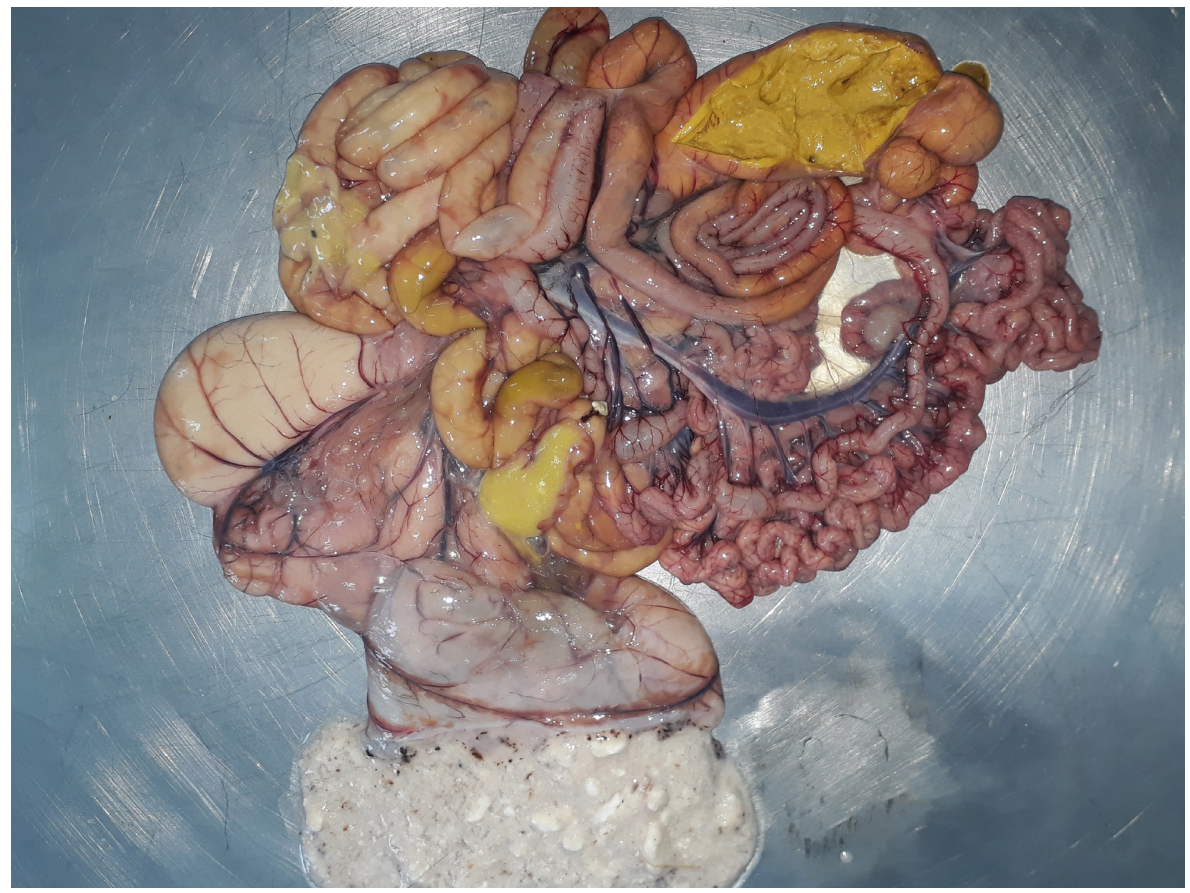

Figure 3. Hyperaemic and loose small intestinal wall. Mucinous yellow-coloured intestinal content filling the lumen of small and large intestines, yellowish mushy caecal content and overfilling of the abomasum with milk coagula, lamb with rotavirus enteritis

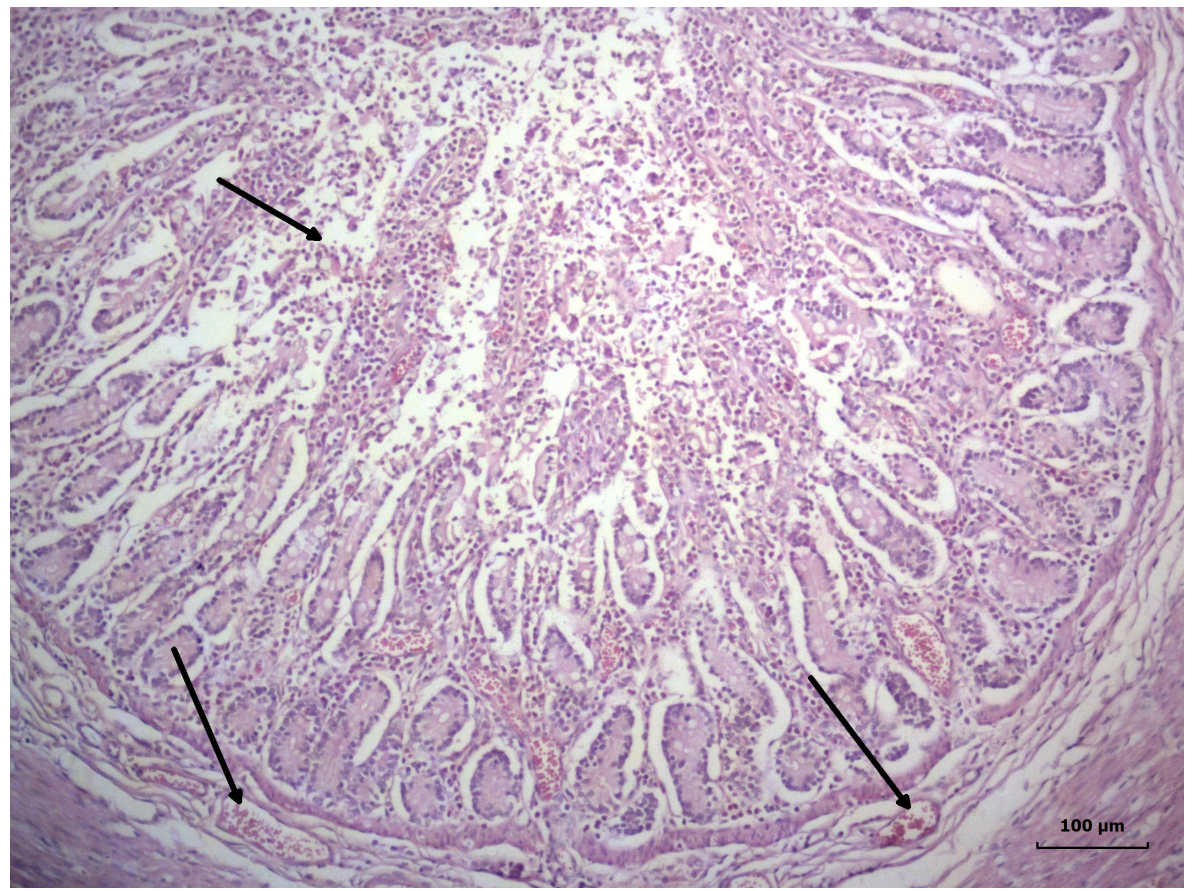

Figure 4. Catarrhal-desquamative inflammation of small intestine with profuse amount of mucoserous exudate, submucosal oedema and intensive vascular hyperaemia in the propria (arrows), jejunum, lamb with coronavirus enteritis, $\mathrm{H} / \mathrm{E}$, Bar $=10 \mu \mathrm{m}$ 
complicated cases with involvement of Escherichia coli where petechial hemorrhages on the epicardium and hematomas on the bicuspid heart valves were found. There were no changes in the larynx, pharynx, nasal cavity mucosa and paranasal sinuses.

\section{Histopathological examinations}

Histologically, lesions were detected along the entire length of the gastrointestinal tract (abomasum, duodenum, jejunum, ileum, caecum, colon and rectum) as well as in the mesenteric lymph nodes. The alterations were comprised of vascular hyperemia in varying intensity in the mucosa and submucosa, submucosal and intermuscular edema with crypts dilatation and glandular hypersecretion. Microscopic villous lesions were indicative of degenerative necrobiotic processes with desquamation, severe atrophy and villous fusion. In coronavirus infection, intestinal lumen exhibited numerous desquamated necrobiotic epithelial cells from the villous surface mixed with mucoserous exudate and intestinal content (Fig. 4).

In rotavirus enteritis, microscopic lesions were in the jejunum and ileum, located in the middle part of the villi and crypts which were strongly dilated, and the propria was infiltrated with numerous lymphocytes. The medullary part of mesenteric lymph nodes was characterized with intense hyperemia in all studied specimens.

\section{Virological examinations}

The used direct immunofluorescence test confirmed the presence of coronavirus and rotavirus antigens in colonic and jejunal tissue sections (Fig. 5 and Fig. 6). Data from these tests confirmed the results from field antigenic tests positive for corona- and rotavirus intestinal infections in tested goat kids and lambs.

\section{DISCUSSION}

The analysis of results from performed clinical, etiological, pathoanatomical and pathomorphological investigations in the neonate, juvenile lambs and goat kids in 9 farms (3 goat farms and 6 sheep farms) gave evidence that involved etiological agents of diagnosed gastroenteritis in these animals were Cryptosporidium parvum, rotaviruses, coronaviruses and Escherichia coli.

We support the findings from previous studies $(4,11)$ that the etiology and epidemiology of gastroenteritis in the neonate, juvenile goat kids, and lambs were closely associated with several factors: the predisposition of neonate goat kids and lambs to intestinal illnesses, nutrition type, and rearing conditions for neonates (goat kids and lambs), hygiene, the immune status of dams in the flock, environmental factors, farm management

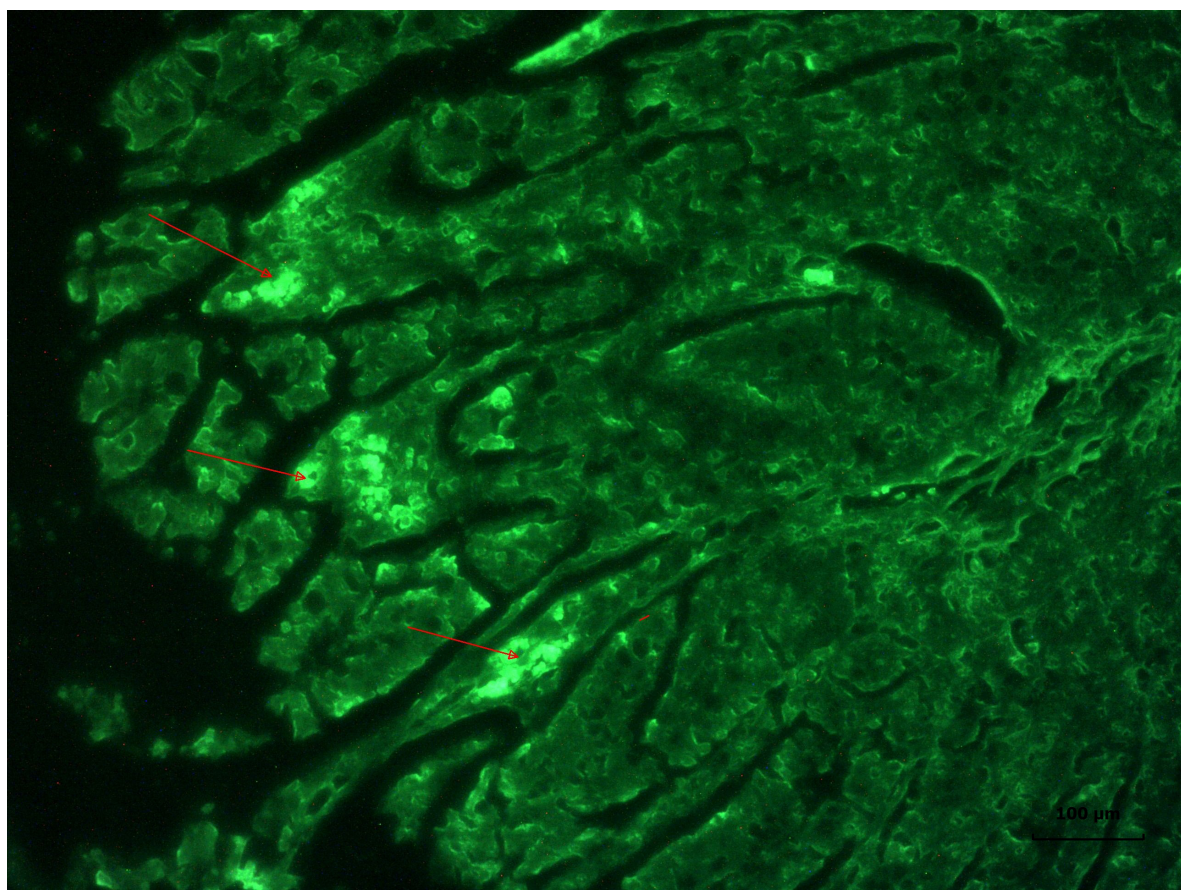

Figure 5. Positive result in direct immunofluorescence test (arrows) for coronavirus antigen in the colon of a 238 lamb with neonatal diarrhea 


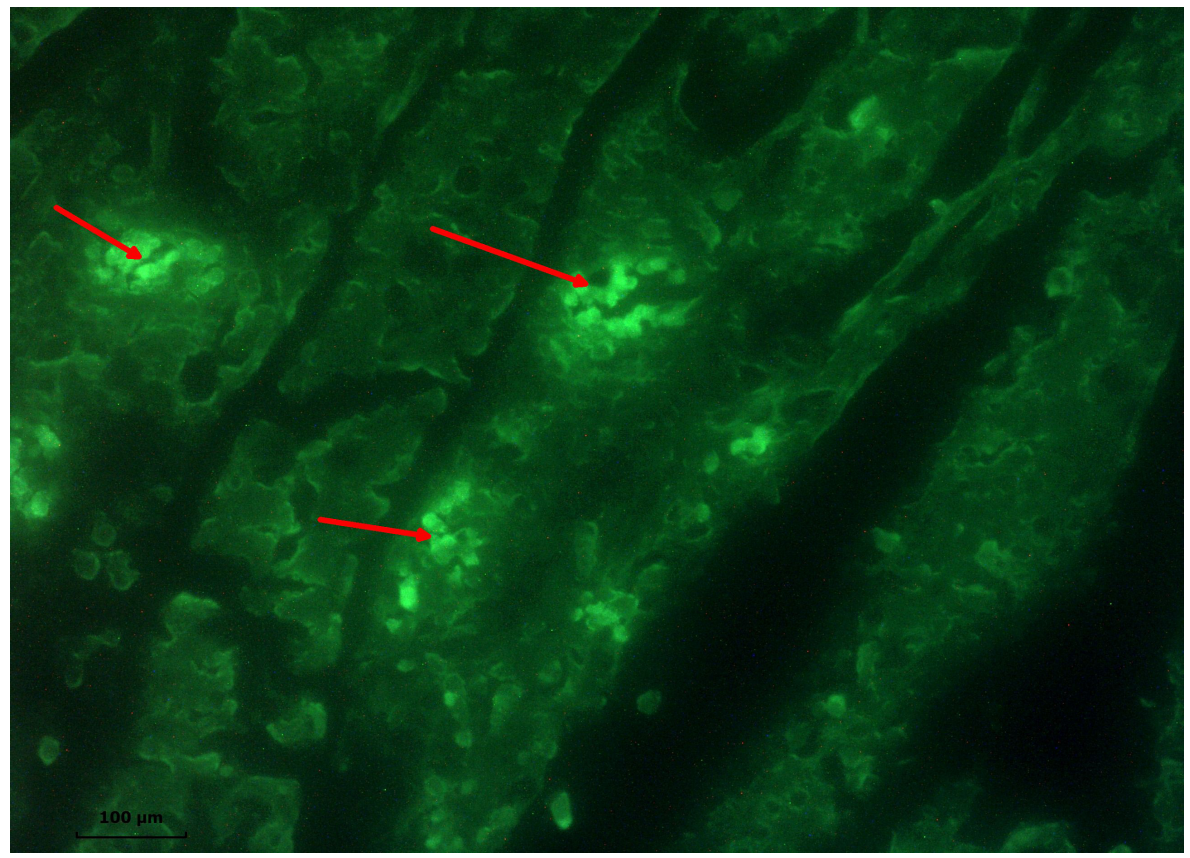

Figure 6. Positive result in direct immunofluorescence test (arrows) for rotavirus antigen in the jejunum of a 243 lamb with neonatal diarrhoea

and various infectious agents (bacteria, viruses, and protozoa).

Our results referring to the etiology and epidemiology of enteritis in small ruminants are largely similar to those of other researchers in this field (7). We also agree with the hypothesis that coinfections can increase the appearance of clinical signs, macro- and micro- lesions, and morbidity and mortality rates (10).

The observed gross changes in the abomasum, small and large intestines of 21 examined carcasses contributed to the elucidation of the pathogenesis and localization of causative agents (Cryptosporidium parvum, rotaviruses, coronaviruses, Escherichia coli) in the different intestinal compartments. These results are in partial agreement with our previous studies on gastrointestinal diseases in newborn and growing calves $(12,13,14)$, as well as with the results of other authors working in the field of gastrointestinal pathology (5).

The performed histopathological studies allowed affirming that coronavirus enteritis affected the superficial part of villi along the length from the duodenum to the colon, resulting in catarrhal-desquamative inflammation (15).

The discussion of results from performed field and laboratory tests allowed affirming that Cryptosporidium parvum, coronaviruses, rotaviruses and $E$. coli $\mathrm{K} 99$ were the main etiological agents of intestinal infections in the neonate, juvenile lambs and goat kids. Coinfections with these pathogens were also observed. We also agree with other reports that the rapid field tests along with immunofluorescence tests were reliable and objective diagnostic methods for the detection of gastrointestinal diseases both in small and large ruminants $(10,15)$.

\section{CONCLUSION}

The established pathoanatomical and histopathological alterations in the gastrointestinal compartments for colibacteriosis, cryptosporidiosis, coronavirus, and rotavirus infections in this study have high diagnostic value and could aid in making a differential diagnosis with eimeriosis (coccidiosis), giardiasis, anaerobic dysentery, salmonellosis and other gastrointestinal illnesses in this category of animals.

\section{CONFLICT OF INTEREST}

The authors declared that they have no potential conflict of interest with respect to the authorship and/or publication of this article.

\section{ACKNOWLEDGEMENTS}

The authors would like to thank colleagues from the Department of General and Clinical Pathology, 
colleagues from practice, as well as farmers for their help and assistance. This research was supported by the Faculty of Veterinary Medicine, Trakia University, Stara Zagora, Bulgaria.

\section{AUTHORS' CONTRIBUTION}

IK participates in epidemiological studies of gastrointestinal diseases in small ruminants, obtaining samples for the planned tests and analysis of all survey data. ID organized the research. IZ participated in the detection of viral agents by IFA method.

\section{REFERENCES}

1. Tzipori, S., Sherwood, D., Angus, K.W., Campebell, I., Gordon, M. (1981). Diarrhoea in lambs: experimental infections with enterotoxigenic Escherichia coli, rotavirus and Cryptosporidium sp. Infect Immun. 33(2): 401-406.

https://doi.org/10.1128/IAI.33.2.401-406.1981

PMid:6268543 PMCid:PMC350712

2. Holland, R.E. (1990). Some infectious causes of diarrhea in young farm animals. Clin Microbiol Rev. 3(4): 345-375.

https://doi.org/10.1128/CMR.3.4.345

PMid:2224836 PMCid:PMC358168

3. Uzzau, S., Leori, G.S., Petruzzi, V., Watson, P.R., Schianchi, G., Bacciu, D., Mazzarello, V., Wallis, T.S., Rubino, S. (2001). Salmonella enterica serovar-host specificity does not correlate with the magnitude of intestinal invasion in sheep. Infect Immun. 69(5): 3092- 3099.

https://doi.org/10.1128/IAI.69.5.3092-3099.2001

PMid:11292728 PMCid:PMC98264

4. Alkan, F., Gulyaz, V., Ozkan Timurkan, M., Iyisan, S., Ozdemir, S., Turan, N., Buonavoglia, C., Martella, V. (2012). A large outbreak of enteritis in goat flocks in Marmara, Turkey, by G8P[1] group A rotaviruses. Arch Virol. 157, 1183-1187. https://doi.org/10.1007/s00705-012-1263-5 PMid:22367501

5. Andrés, S., Jiménez, A., Sánchez, J., Alonso, J.M., Gomez, L., López, F., Rey, J. (2007). Evaluation of some etiological factors predisposing to diarrhoea in lambs in "La Serena" (Southwest Spain). Small Ruminant Res. 70(2-3): 272-275.

https://doi.org/10.1016/j.smallrumres.2006.04.004 PMid:32288215 PMCid:PMC7135622
6. Gokce, E., Erdogan, H.M. (2009). An epidemiological study on neonatal lamb healthy. Kafkas Univ Vet Fak Derg. 15(2): 225-236.

7. Martella, V., Decaro, N., Buonavoglia, C. (2015). Enteric viral infections in lambs or kids. Vet Microbiol. 181(1-2): 154-160.

https://doi.org/10.1016/j.vetmic.2015.08.006

PMid:26321129 PMCid:PMC7131559

8. Papp, H., Malik, Y.S., Farkas, S.L., Jakab, F., Martella, V., Banyai, K. (2014). Rotavirus strains in neglected animal species including lambs, goats and camelids. Virus Disease, 25(2): 215-222.

https://doi.org/10.1007/s13337-014-0203-2

PMid:25674588 PMCid:PMC4188177

9. Steele, D., Geyer, A., Gerdes, G. (2004). Rotavirus infections. In: Coetzer, J.A.W., Tustin, R.C. (Eds.), Infectious diseases of livestock (pp. 1256-1264). New York: Oxford University

10. Matthijnssens, J., Potgieter, C.A., Ciarlet, M., Parreño, V., Martella, V., Bányai, K., Garaicoechea, L., et al. (2009). Are human $\mathrm{P}[14]$ rotavirus strains the result of interspecies transmissions from sheep or other ungulates that belong to the mammalian order Artiodactyla. J Virol. 83(7): 2917-2929.

https://doi.org/10.1128/JVI.02246-08

PMid:19153225 PMCid:PMC2655590

11. Uzzau, S., Figueroa-Bossi, N., Rubino, S., Bossi, L. (2001). Epitope tagging of chromosomal genes in Salmonella. PNAS. 98(26): 15264-15269.

https://doi.org/10.1073/pnas.261348198

PMid:11742086 PMCid:PMC65018

12. Kalkanov, I., Dimitrov, K., Dinev, I. (2014). Clinicomorphological studies in a case of complicated neonatal calf diarrhea. Animal Studies \& Veterinary Medicine IV(5): 37-43. [In Bulgarian]

13. Kalkanov, I., Dinev, I., Dimitrov, K., Iliev, P. (2015). Clinical and morphological investigationis in a spontaneous Cryptosporidium enteritis outbreak in calves. Bulg J Vet Med. 19(4): 334-339.

https://doi.org/10.15547/bjvm.924

14. Kalkanov, I., Dinev, I., Aleksandrov, M., Dimitrov, K., Zarkov, I. (2016). Morphological and etiological investigations in a rotaviral enteritis outbreak in calves. Kafkas Univ Vet Fak Derg. 22(2): 309-313.

15. Naylor, M. (1990). Diarrhoea in neonatal ruminants. In: Smith B.P. (Ed.), Large animal internal disease. Chapter 32: Diseases of the alimentary tract (pp. 348-353). Saint Louis: Mosby Publishing 